\title{
Assessment of Environmental Risk from Coal Using Neutron Activation Analysis
}

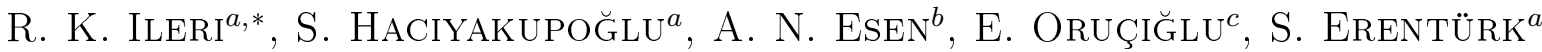 \\ ${ }^{a}$ Energy Institute, Istanbul Technical University, 34469, Maslak-Istanbul, Turkey \\ ${ }^{b}$ Faculty of Engineering, Istanbul Bilgi University, 34060, Eyup, Istanbul, Turkey \\ ${ }^{c}$ Faculty of Mines, Istanbul Technical University, 34469, Maslak-Istanbul, Turkey
}

\begin{abstract}
This study aimed to determine element concentration in coal samples and to assess $\mathrm{Co}, \mathrm{Cr}, \mathrm{Se}$, Th and U leaching from coals exposed to a simulated coal cleaning process. Coal samples taken from a local area of Turkey were grounded and exposed to water for one month period. Then the cleaned samples were filtered and dried. The elemental concentrations in the samples before and after the cleaning procedure were determined by relative neutron activation analysis (NAA). Raw and water cleaned coal samples were irradiated in central irradiation tube of TRIGA MARK II Research Reactor at $250 \mathrm{~kW}$ for $6 \mathrm{~h}$ and measured for their activities by using high resolution gamma spectroscopy system. The results showed that leaching percentage for Se is up to $100 \%$ and for $\mathrm{Co}, \mathrm{Cr}, \mathrm{Th}$ and $\mathrm{U}$ up to $71 \%, 17 \%, 30 \%, 28 \%$ respectively.
\end{abstract}

DOI: $10.12693 /$ APhysPolA.127.1010

PACS: 29.30.-h, 89.30.ag, 07.88.+y

\section{Introduction}

Energy demand of contemporary world is increasing because of development of high technologies and industrial activities. Coal is the most significant natural energy resource and it satisfies $27 \%$ of energy demand in the world [1]. Although it takes a great effort of nation to satisfy its energy demand, it threatens environment, especially air and surface and ground waters.

In the past, rising environmental awareness and productivity affected this industry. Impurities in the coal affect energy production efficiency. Moreover, hazardous elements resulted from combustion can contaminate the air and can be inhaled through respiratory way by living organisms. Answering these concerns, the coal enrichment processes were given a special attention. Enrichment process that comprises physical or chemical processes is an essential part of efficient combustion in thermal power plants. However, chemical cleaning process is in development so its efficiency and cost cannot be predicted. Consequently, physical cleaning was preferred instead of former one. In the late of 1970s, Environmental Protection Agency (EPA) encouraged the coal cleaning process based on density separation procedure and this procedure is still mostly used $[2,3]$. In the coal cleaning process, coal particles in water are exposed to centrifugal forces to separate impurities by gravitational force. Lighter particles swim on the surface of liquid and heavier particles sink to the bottom. The impurities are removed by separation of the upper layer from the bottom. The excessive amount of solution resulting from this process is directly disposed into the environment. In this way, the exposed impurities from coal contaminate the soil and

*corresponding author; e-mail: ileriru@itu.edu.tr water resources. After wet process, the cleaned coal particles are dried and prepared for the next process [3-5]. Coal mining activities and manufacturing processes especially cleaning process may cause release of metals such as $\mathrm{Co}, \mathrm{Cr}, \mathrm{Se}$, Th and $\mathrm{U}$ to the environment and leading to leaching of these elements [2].

In several studies it is demonstrated that intake of Co, $\mathrm{Cr}$, Se, Th and U affect both human and animal health and caused serious diseases such as cancer, asthma, body deformation and genetic mutation [6-11]. NAA is suitable method for elemental analysis due to its sensitivity, accuracy and simple sample preparation procedure. It has been widely used in numerous areas of science including environmental sciences. Number of studies describing analysis of coal with NAA has been done recently [12-14].

The aim of this study is to determine the concentration of $\mathrm{Co}, \mathrm{Cr}$, Se, Th and $\mathrm{U}$ in raw and simulated cleaned coal samples taken from a local area of Turkey by neutron activation analysis to analyze the effect of a simulated cleaning process.

\section{Material and method}

\subsection{Sample preparation}

Coal samples were collected by random sampling from a main coal mine which is used in a power plant located in south east of Turkey. Raw coal samples were crushed and grinded with a mill, then sampled by systematic grid sampling for homogenization [15]. Bidistilled water was added to coal samples providing the solid/liquid ratio $2 \%$. After one month waiting time, all prepared suspensions were filtered and air dried. A gravimetric method was applied for the determination of the dry matter content of the samples that are not used in analyses [16]. Dry matter content, $f_{d m}$, of each sample was expressed as a percentage of mass using the Eq. 2.1 where $m_{c}$ is the mass of the empty container, $m_{d s}$ is the total mass of the container and dried sample and $m_{w s}$ is the total mass of 
the container and moist sample.

$$
f_{d m}=\left[\left(m_{d s}-m_{c}\right) /\left(m_{w s}-m_{c}\right)\right] \times 100 .
$$

\subsection{Irradiation and gamma spectroscopy}

$250 \mathrm{mg}$ of raw and cleaned coal samples and references were packed in aluminum foil for irradiation. Certified reference material (CRM) from the National Institute for Standards and Technology (NIST SRM 1633b) were used as a standard [17]. Effect of flux fluctuation in samples were determined by $\mathrm{Au}$ monitors which were prepared with $\mathrm{AuCl}_{4} \mathrm{H} \cdot 3 \mathrm{H}_{2} \mathrm{O}$ (99.5\% purity, Merck) solution. Certain amount of this solution was added by dropping at paper disks and covered with polyethylene bags after evaporation. The used micropipette (BRAND) was calibrated gravimetrically before measurements.

A total samples containing 12 raw coal samples, 12 cleaned coal samples and flux monitors were heaped together and put into irradiation tube as a sandwich. Neutron flux monitors are placed in each sample row and a blank (packed aluminum foil) is placed in a sample row. Irradiation was applied in ITU TRIGA MARK II Research Reactor of Istanbul Technical University at $250 \mathrm{~kW}$ for $6 \mathrm{~h}$. The thermal neutron fluence rate in the central irradiation channel is approximately $1.13 \times$ $10^{12} \mathrm{~cm}^{-2} \mathrm{~s}^{-1}$. Radionuclides in Table I, resulting from activation by thermal neutron capture reactions, were determined by using gamma spectroscopy technique.

Irradiated samples and flux monitors were measured by HPGe detector (ORTEC GMX n-type) with a relative efficiency of $14.4 \%$ and a resolution of $2.0 \mathrm{keV}$ at $1332.5 \mathrm{keV}$ photons of ${ }^{60} \mathrm{Co}$. The detector was connected to a digital signal processing analyzer (ORTEC DSPEC jr. 2.0) operating through Gamma Vision-32 spectroscopy software. To obtain good count statistics depending on the activities of samples, samples were measured approximately 3 to 18 days after irradiation. Counting times were $1-2$ hours for raw coal samples and 4 hours for cleaned coal samples.

Nuclear properties of investigated elements [18]. TABLE I

\begin{tabular}{c|c|c|c|c|c}
\hline \hline $\begin{array}{c}\text { Ele- } \\
\text { ment }\end{array}$ & $\begin{array}{c}\text { Radio- } \\
\text { nuclide }\end{array}$ & $\begin{array}{c}\text { Nuclear } \\
\text { reaction }\end{array}$ & $\begin{array}{c}\text { NCS } \\
{[\text { barn] }}\end{array}$ & $\begin{array}{c}\text { Half-life } \\
{[\text { days }]}\end{array}$ & $\begin{array}{c}\gamma^{* *} \\
{[\mathrm{keV}]}\end{array}$ \\
\hline $\mathrm{U}$ & ${ }^{238} \mathrm{U}$ & ${ }^{238} \mathrm{U}(\mathrm{n}, \gamma)^{239} \mathrm{U}\left(\beta^{-}\right)^{239} \mathrm{~Np}$ & 2.68 & 2.3565 & 277.599 \\
$\mathrm{Th}$ & ${ }^{232} \mathrm{Th}$ & ${ }^{232} \mathrm{Th}(\mathrm{n}, \gamma)^{233} \mathrm{~Pa}$ & 7.37 & 26.967 & 312.17 \\
$\mathrm{Cr}$ & ${ }^{50} \mathrm{Cr}$ & ${ }^{50} \mathrm{Cr}(\mathrm{n}, \gamma)^{51} \mathrm{Cr}$ & 15.90 & 27.702 & 320.0842 \\
$\mathrm{Co}$ & ${ }^{59} \mathrm{Co}$ & ${ }^{59} \mathrm{Co}(\mathrm{n}, \gamma)^{60} \mathrm{Co}$ & 37.18 & 1924.061 & 1173.237 \\
$\mathrm{Se}$ & ${ }^{74} \mathrm{Se}$ & ${ }^{74} \mathrm{Se}(\mathrm{n}, \gamma)^{75} \mathrm{Se}$ & 51.80 & 119.779 & 136.0008
\end{tabular}

*Thermal neutron cross section.

** $\gamma$-peak used.

Concentrations of elements were calculated from comparison of peak areas in measured spectra of sample and standard comparator by using Eq. 2.2 in which $m_{x, \text { unk }}$ is the element concentration in the unknown sample $\left(\mathrm{mg} \mathrm{kg}^{-1}\right), m_{x, s t d}$ is the element concentration in the standard comparator $\left(\mathrm{mg} \mathrm{kg}^{-1}\right), C$ is the net count rate in the $\gamma$-ray peak of radionuclide, $t_{d}$ is the decay time to start of measurement $(\mathrm{s}), t_{m}$ is the live time of the measurement $(\mathrm{s}), \lambda$ is the decay constant $\left(\mathrm{s}^{-1}\right), R_{\Phi}$ is the ratio of thermal neutron fluxes for standard comparator and unknown sample [19].

$$
\begin{gathered}
m_{x, \text { unk }}=m_{x, \text { std }}\left(\frac{C}{\exp \left(-\lambda t_{d}\right) \times\left(1-\exp \left(-\lambda t_{m}\right)\right)}\right)_{\text {unk }} \\
/\left(\frac{C}{\exp \left(-\lambda t_{d}\right) \times\left(1-\exp \left(-\lambda t_{m}\right)\right)}\right)_{\text {std }} \times R_{\Phi} . \quad(2.2)
\end{gathered}
$$

The accuracy of results was statistically evaluated using $E_{n}$ test for comparison between experimental result and certified value of the reference material NIST 2702 [20]. The $E_{n}$ number is defined in Eq. 2.3 where $x_{\text {lab }}$ and $x_{\text {cer }}$ are the experimental and certified data; $u_{\text {lab }}$ and $u_{\text {cer }}$ are the experimental and certified uncertainties at $95 \%$ confidence level, respectively. The result is accepted if $E_{n}<1$, and not accepted if $E_{n}>1$ [21].

$$
E_{n}=\left|x_{\text {lab }}-x_{\text {cer }}\right| / \sqrt{u_{\text {lab }}^{2}-u_{\text {cer }}^{2}} \text {. }
$$

\section{Results and discussion}

Table II gives the elemental concentrations with their uncertainties and $E_{n}$ values for each coal sample before and after simulated cleaning processes. Statistically, the elemental analysis results are acceptable because $E_{n}<1$. Only the $E_{n}$ value of Th is approximately equal to 1 . The reason may be the small amount of the element in the samples.

Results are compatible with the comprehensive study conducted for different coal mine areas of Turkey that found concentrations of $\mathrm{Co}, \mathrm{Cr}$, Se and $\mathrm{U}$ in the range of $1.4-18,13-270,0.51-17$ and $0.74-34 \mathrm{mg} / \mathrm{kg}$, respectively [22].

Comparison of elemental concentrations before and after cleaning indicates reduction of these elements after cleaning. The leaching ratio changed between 11-71\% for $\mathrm{Co}, 0-17 \%$ for $\mathrm{Cr}, 0-100 \%$ for Se, $0-30 \%$ for $\mathrm{Th}$ and 0-28\% for U. The very little difference between thorium concentrations of pure and cleaned samples could be attributed to very insoluble and immobile structure of thorium in natural waters [23].

There are guidelines for drinking water for evaluating risk from hazardous elements [24, 25]. According to these guidelines, Table III gives permissible concentrations of investigated elements. Considering leaching ratios of the elements for simulated cleaning conditions, the element concentrations in coal cleaning waters can be higher than permissible concentrations.

Permissible concentrations of elements of interest [23, 24].

\section{TABLE III}

\begin{tabular}{l|c|c|c|c|c}
\hline \hline \multicolumn{1}{c|}{ Element } & $\mathrm{U}$ & $\mathrm{Th}$ & $\mathrm{Se}$ & $\mathrm{Co}$ & $\mathrm{Cr}$ \\
\hline $\begin{array}{l}\text { Concentration }[\mathrm{mg} / \mathrm{L}] \\
\text { *not avaliable }\end{array}$ & 0.03 & $\mathrm{na}^{*}$ & 0.04 & $0.2-5$ & 0.05 \\
\end{tabular}


Element concentrations before and after simulated cleaning processes (nd: not detected).

\begin{tabular}{|c|c|c|c|c|c|c|c|c|c|c|}
\hline \multirow{4}{*}{ Sample } & \multicolumn{10}{|c|}{ Element concentration $x_{l a b} \pm u_{l a b}(\mathrm{mg} / \mathrm{kg})$} \\
\hline & Co & $\mathrm{Cr}$ & Se & Th & $\mathrm{U}$ & $\mathrm{Co}$ & $\mathrm{Cr}$ & $\mathrm{Se}$ & Th & $\mathrm{U}$ \\
\hline & $E_{n}=0.30$ & $E_{n}=0.45$ & $E_{n}=0.10$ & $E_{n}=1.03$ & $E_{n}=0.03$ & $E_{n}=0.30$ & $E_{n}=0.45$ & $E_{n}=0.10$ & $E_{n}=1.03$ & $E_{n}=0.03$ \\
\hline & \multicolumn{5}{|c|}{ Pure coal samples } & \multicolumn{5}{|c|}{ Cleaned coal samples } \\
\hline 1 & $8 \pm 0.5$ & $240 \pm 4.8$ & $7 \pm 0.9$ & $3 \pm 0.2$ & $16 \pm 1.0$ & $6 \pm 0.5$ & $200 \pm 4.5$ & $7 \pm 0.9$ & $3 \pm 0.2$ & $13 \pm 0.9$ \\
\hline 2 & $5 \pm 0.0$ & $25 \pm 2.4$ & $1 \pm 0.6$ & $1 \pm 0.1$ & $3 \pm 0.2$ & $3 \pm 0.3$ & $25 \pm 1.6$ & 0.00 & $1 \pm 0.1$ & $2 \pm 0.2$ \\
\hline 3 & $8 \pm 0.4$ & $174 \pm 4.3$ & $6 \pm 0.9$ & $2 \pm 0.2$ & $11 \pm 1.0$ & $5 \pm 0.5$ & $174 \pm 5.1$ & $6 \pm 0.8$ & $1 \pm 0.2$ & $11 \pm 0.7$ \\
\hline 4 & $8 \pm 0.5$ & $409 \pm 7.0$ & $10 \pm 1.0$ & $4 \pm 0.2$ & $15 \pm 1.0$ & $7 \pm 0.6$ & $374 \pm 6.5$ & $6 \pm 0.8$ & $3 \pm 0.2$ & $14 \pm 1.0$ \\
\hline 5 & $10 \pm 0.3$ & $151 \pm 4.4$ & $6 \pm 0.8$ & $1 \pm 0.1$ & $12 \pm 0.8$ & $4 \pm 0.4$ & $144 \pm 4.4$ & $5 \pm 0.7$ & $1 \pm 0.1$ & $11 \pm 1.0$ \\
\hline 6 & $5 \pm 0.0$ & $26 \pm 1.5$ & $0.72 \pm 0.4$ & $1 \pm 0.1$ & $3 \pm 0.3$ & $3 \pm 0.3$ & $25 \pm 2.0$ & ${ }^{n d}$ & $1 \pm 0.1$ & $4 \pm 0.3$ \\
\hline 7 & $20 \pm 1.2$ & $209 \pm 4.9$ & $8 \pm 0.9$ & $5 \pm 0.3$ & $16 \pm 1.1$ & $6 \pm 1.0$ & $187 \pm 7.0$ & $6 \pm 0.8$ & $4 \pm 0.2$ & $14 \pm 0.9$ \\
\hline 8 & $9 \pm 0.4$ & $117 \pm 4.1$ & $6 \pm 0.8$ & $1 \pm 0.2$ & $18 \pm 1.1$ & $4 \pm 0.4$ & $104 \pm 3.3$ & $5 \pm 0.8$ & $1 \pm 0.2$ & $14 \pm 0.9$ \\
\hline 9 & $10 \pm 0.4$ & $103 \pm 3.6$ & $-{ }^{n d}$ & $1 \pm 0.1$ & $9 \pm 0.8$ & $5 \pm 0.4$ & $102 \pm 3.6$ & $2 \pm 0.7$ & $1 \pm 0.1$ & $7 \pm 0.5$ \\
\hline 10 & $13 \pm 0.8$ & $127 \pm 3.1$ & $5 \pm 0.8$ & $4 \pm 0.2$ & $14 \pm 0.9$ & $6 \pm 0.8$ & $109 \pm 5.4$ & $2 \pm 0.8$ & $3 \pm 0.2$ & $12 \pm 0.8$ \\
\hline 11 & $15 \pm 0.9$ & $124 \pm 2.6$ & $5 \pm 0.7$ & $3 \pm 0.1$ & $18 \pm 1.2$ & $6 \pm 0.8$ & $118 \pm 2.6$ & $3 \pm 0.6$ & $2 \pm 0.1$ & $18 \pm 1.2$ \\
\hline 12 & $10 \pm 0.7$ & $97 \pm 2.5$ & $7 \pm 0.8$ & $4 \pm 0.1$ & $26 \pm 1.7$ & $6 \pm 0.6$ & $96 \pm 2.3$ & $5 \pm 0.6$ & $4 \pm 0.2$ & $23 \pm 1.5$ \\
\hline
\end{tabular}

\section{Conclusions}

Selected element concentrations are determined by relative INAA method in the coal samples from a local area of Turkey and leaching of these elements by simulated cleaning are discussed. Element concentrations are determined with high accuracy. The simulated cleaning process of the coal samples showed different leaching ratios. Considering it is a simulated cleaning method, leaching ratios may differ from the conventional coal cleaning processes. It can be said that dispersion of the elements to the environment is highly possible due to leaching. To prevent hazardous trace element dispersion to the environment, monitoring of the process waters could be necessary. We suppose that this study may contribute to make elemental comparison of coals and to emphasize the importance of coal cleaning procedures and environmental protection.

\section{References}

[1] X. Lu, C. Zhao, C. Chen, W. Liu, Radiat. Phys. Chem. 81, 1827 (2012).

[2] I. Demir, L. Khan, in: Advances in Coal Cleaning (Illinois State Geological Survey), American Chemical Society Annual Meeting, Anaheim, 1999.

[3] J.A. Cavallaro, G.A. Gibbon, A.W. Deurbrouck, A Washability and Analytical Evaluation of Potential Pollution from Trace Elements in Coal, U.S. Department of Energy, Division of Solid Fuel Mining and Preparation, Washington, DC 1978.

[4] Technical Support Document, The Coal Sectors Proposed Rule for Mandatory Reporting of Greenhouse Gases, Office of Air and Radiation U.S. Environmental Protection Agency 2009.

[5] Y. Yudovich, M.P. Ketris, Int. J. Coal Geol. 61, 141 (2005).

[6] Agency for Toxic Substances and Disease Registry (ATSDR). Toxicological Profile for Thorium, U.S. Department of Health and Human Services, Public Health Service U.S. Atlanta, GA 1990.

[7] Agency for Toxic Substances and Disease Registry (ATSDR). Toxicological Profile for Uranium, U.S. Department Of Health And Human Services Agency for Toxic Substances and Disease Registry 2013.
[8] M. Stanislawska, B. Janasik, W. Wasowicz, Talanta 117, 14 (2013).

[9] J.H. Kim, H.J. Gibb, P.D. Howe, in: Cobalt and Inorganic Cobalt Compounds, WHO 2006.

[10] H.A. Kehrig, T.G. Seixas, A.P.M.D. Beneditto, O. Malm, Ecotox. Environ. Safe. 93, 156 (2013).

[11] J.K. Fawell, G.F. Combs, in: Selenium in Drinkingwater , WHO Guidelines for Drinking-water Quality 2011.

[12] M.B. Alamin, J. Radioanal. Nucl. Ch. 216, 41 (1996).

[13] F. Goodarzi, Int. J. Coal Geol. 65, 17 (2006).

[14] G.M. Eskenazy, Int. J. Coal Geol. 78, 192 (2009).

[15] IAEA, Soil Sampling for Environmental Contaminants, Vienna 2004.

[16] ASTM, Standard Test Method for Laboratory Determination of Water (Moisture) Content of Soil and Rock by Mass, 1999.

[17] NIST, Certificate of Analysis Standard Reference Material 1633 b Constituent Elements in Coal Fly Ash, National Institute of Standards \& Technology 2004.

[18] R.B. Firestone, Table of Isotopes, in: Chu, S.Y.F. (CD-ROM ed.), 8th ed. Wiley, New York 1998.

[19] R.R. Greenberg, P. Bode, E.A. De Nadai Fernandes, Spectrochim. Acta Part B 66, 193 (2011).

[20] NIST, NIST, Certificate of Analysis Standard Reference Material 2702 NIST, Inorganics in Marine Sediment, National Institute of Standards \& Technology 2012.

[21] ISO/IE C Guide 43-2, Proficiency testing by interlaboratory comparisons- Part 2: Selection and use of proficiency testing schemes by laboratory accreditation bodies, 1997.

[22] C.A. Palmer, E. Tuncalı, K.O. Dennen, T.C. Coburn, R.B. Finkelman, Int. J. Coal Geol. 60, 85 (2004).

[23] D. Lancmuir, J.S. Herman, Geochim. Cosmochim. Ac. 44, 1753 (1980).

[24] T. Abbasi, S.A. Abbasi, Water Quality Indices, Elsevier United 2007.

[25] WHO, Guidelines for Drinking-water Quality, 4th edition, 2011. 